\title{
A CENTRALIDADE DAS TAREFAS NAS PRÁTICAS ESCOLARES CONSTRUTIVISTAS 1
}

Luelí Nogueira Duarte e Silva**2

\section{RESUMO}

Este artigo propõe-se a discutir o papel central que as tarefas escolares passaram a assumir no processo ensino-aprendizagem nas práticas educativas contemporâneas. A centralidade das tarefas escolares expressa a tradução do princípio construtivista de que a construção do conhecimento do aluno advém de sua ação. $O$ conceito de ação, fundante destas práticas, encontra sua fundamentação na teoria genética de Piaget e justificativa teórica no pragmatismo de John Dewey.

Palavras-chave: tarefas escolares, ação, teorias psicológicas

Este trabalho tem por finalidade analisar e discutir o papel central que as tarefas escolares passaram a assumir no processo ensino-aprendizagem nas práticas educativas contemporâneas. Consideram-se tarefas escolares as atividades planejadas, elaboradas ou propostas pelos professores, ou indicadas nas apostilas adotadas e realizadas em classe ou em casa pelos alunos, referindo-se a conteúdos escolares, objetivando a aprendizagem discente.

A pesquisa pretendeu estudar as tarefas escolares inerentes às práticas educativas denominadas construtivistas, 1 entendendo por práticas construtivistas aquelas que, sob as mais diversas versões ou

denominações, são orientadas por um conjunto de princípios, parâmetros e diretrizes fundamentados nas teorias psicológicas do desenvolvimento e da aprendizagem que preconizam que o aluno constrói seu conhecimento mediante a ação. 

vespertino, uma no primeiro semestre e a outra, no segundo semestre.

A análise dos dados evidenciou a importância das tarefas escolares e a sua centralidade no processo ensino-aprendizagem. A percepção dessa centralidade como uma característica distintiva das práticas pedagógicas observadas levou à eleição das tarefas escolares como objeto de estudo.

Com o propósito de compreender melhor a questão, procedeu-se novamente à leitura de todas as observações das seis escolas e das entrevistas, identificando a dinâmica e a ritualização das aulas em cada uma das escolas, descrevendo e analisando as tarefas escolares, visando captar os elementos de unidade e de dispersão, para, finalmente, descrever e analisar a rotina escolar, procurando contemplar as particularidades e as especificidades de cada escola e de cada prática educativa.

A releitura confirmou o que a primeira aproximação sugeria: as tarefas escolares passaram a assumir a centralidade do processo ensino-aprendizagem, a despeito dos qualificativos que designam essas práticas escolares. Essa centralidade manifestava-se na transformação da aula em espaço para os alunos realizarem, sucessivamente, atividades propostas pelo professor ou indicadas nas apostilas adotadas, supondo que o processo de aprendizagem adviria da ação.

As constatações suscitaram os seguintes questionamentos: como compreender essa centralidade das tarefas escolares nas práticas escolares construtivistas? O que expressa a exacerbação da atividade do aluno?

Para discutir e compreender o significado da centralidade da ação na prática pedagógica, foi necessário, em primeiro lugar, verificar, no campo próprio do construtivismo, se as práticas escolares das escolas observadas constituíam-se como prática escolar construtivista e se os alunos eram ativos no sentido que o construtivismo concebe a ação; em segundo lugar, identificar e analisar a justificativa teórica que sustenta o princípio de que a ação gera a aprendizagem, e, finalmente, elaborar uma análise crítica referente a essa centralidade.

As tarefas escolares nas práticas educativas construtivistas 
Para investigar se as escolas observadas constituíam-se como prática escolar construtivista e se os alunos eram ativos tal como o construtivismo concebe a ação, recorreu-se aos autores de orientação construtivista, especialmente César Coll,4 por ser considerado um dos principais sistematizadores e articuladores do construtivismo na atualidade, com o objetivo de extrair de seus estudos as premissas, as orientações e os parâmetros de um modelo construtivista dos processos educativos escolares e apreender o significado da atividade do aluno no processo ensino-aprendizagem.

O construtivismo era (e ainda é) compreendido como uma concepção de aprendizagem escolar que

situa a atividade mental construtiva do aluno na base dos processos de desenvolvimento pessoal que a educação escolar trata de promover. Mediante a realização de aprendizagens significativas, o aluno constrói, modifica, diversifica e coordena os seus esquemas, estabelecendo, deste modo, redes de significados que enriquecem o seu conhecimento do mundo físico e social e potenciam o seu crescimento pessoal. (Coll, 1994, p. 136-137)

Embora a atividade auto-estruturante esteja na base do processo de construção do conhecimento e tenha com efeito algumas leis próprias que devem ser respeitadas, isto não implica, em absoluto, que seja impermeável à influência do professor e da intervenção pedagógica (...) influência que faz com que a atividade do aluno seja ou não auto-estruturante e tenha, definitivamente, um maior ou menor impacto sobre a aprendizagem escolar (Coll, 1994, p. 101).

Nessa conceituação, encontram-se claramente explicitadas as duas premissas fundamentais do construtivismo: a ação do aluno e a ação do professor. A ação do aluno, entendida como atividade auto-estruturante ou atividade mental construtiva, considera o aluno como o protagonista do processo ensino-aprendizagem, tendo em vista que a construção de sua aprendizagem ocorre, supostamente, mediante sua ação sobre os objetos.

A ação do professor, entendido como mediador, como facilitador ou como condutor desse processo, compreende o professor como o agente fundamental que possibilita que a atividade do aluno seja auto-estruturante. 
Essas premissas, apesar de essenciais, não bastam para configurar um modelo ensino-aprendizagem de natureza construtivista, porque, de acordo com Coll (1994, p. 137), evidenciam a ambigüidade que "preside o papel que o professor deve ter nas propostas pedagógicas que situam na atividade auto-estruturante do aluno o ponto de partida da construção do conhecimento". Esse modelo concebe o aluno como o "verdadeiro artífice e único responsável do processo de aprendizagem" e, ao mesmo tempo, atribui um papel decisivo ao professor como "orientador, guia e facilitador de tal aprendizagem mediante a colocação em ponto de atividades instrutivas".

Na tentativa de solucionar o impasse, Coll recorreu às teses de Vygotsky sobre o papel da interação social no desenvolvimento dos processos psicológicos superiores, inferindo a possibilidade de estabelecer um paralelismo entre as relações interpessoais durante os primeiros anos de vida e a relação professor-aluno. A tese da interatividade explica que $\mathrm{o}$ ato educativo não pode ser compreendido apenas como uma atividade auto-estruturante, individual $e$ intrapessoal, relegando ao professor um lugar relativamente secundário; ao contrário, o processo ensino-aprendizagem deve ser visto como composto por três instâncias interativas: o aluno, o objeto e o professor.

Nesse processo, o professor é aquele "encarregado de planejar sistematicamente as tarefas de aprendizagem" (Coll,1994, p.103), entendido como mediador aquele que faz com que as tarefas de aprendizagem ofereçam as condições para a atividade autoestruturante do aluno se concretize e se efetive.

A unidade básica do processo ensino-aprendizagem é a "atividade articulada e conjunta do aluno e do professor em torno da realização das tarefas escolares" (Coll, 1994, p.103). Porém, Coll afirma que a atividade auto-estruturante do aluno continua sendo a base do processo de construção do conhecimento, só que essa atividade está "inscrita de fato no domínio da interação ou na interatividade professor e aluno" (p. 103).

Para a efetiva realização da atividade auto-estruturante do aluno é necessário que o professor adote uma postura construtivista, crie um ambiente e situações de aprendizagem, dentre elas, as tarefas escolares, que possibilitem a construção e a reconstrução dos esquemas de conhecimento. Ou, dito de outra forma, na abordagem construtivista, o professor deve ser o criador 
daquilo que Garcia (1997, p. 54) chama de "as oportunidades de descobrir". Segundo Deval (1997, p.163), "o professor deve se limitar a criar as condições necessárias para que os alunos aprendam", ou, ainda, de acordo com Brooks e Brooks (1997, p. 115): "o modo pelo qual um professor estrutura uma tarefa determina o grau com que os alunos podem ser autônomos e mostrar iniciativa".

Pode-se inferir que a adoção dessas premissas acarreta um conjunto de modificações nos processos educativos escolares, já assinalados em alguns estudos sobre essa temática. De modo geral, pode-se afirmar que a ênfase ao processo ensino-aprendizagem é colocada no pólo da aprendizagem, pois o aluno é considerado o protagonista do processo e o construtor ativo de seu próprio conhecimento, acarretando menor acentuação do pólo ensino, já que o professor é aquele que conduz, facilita o ato de aprender do aluno, cabendo-lhe criar situações de aprendizagens, dentre elas as tarefas escolares, que permitam ao aluno desenvolver a atividade auto-estruturante.

As tarefas escolares são consideradas, nessa perspectiva, o elemento de mediação entre a ação do aluno, a ação do professor e a aprendizagem, devendo priorizar o desenvolvimento da atividade auto-estruturante. Desse modo, a avaliação passa a ser processual, pontual, constante e diária, bem como o planejamento, a organização e a seleção dos conteúdos.

Além disso, a estruturação física da sala de aula pode apresentar uma organização diferente das concepções anteriores de ensino, de modo a propiciar um ambiente mais dinâmico, mais cooperativo e mais interativo.

Ao confrontar as premissas e os aspectos que caracterizam um modelo construtivista dos processos educativos escolares com a rotina escolar das seis escolas, verifica-se, de modo geral, a existência de alguns indicadores, com maior ou menor incidência, conforme a escola, em relação ao processo ensino-aprendizagem, à relação professor-aluno, às tarefas escolares e à estruturação física da sala de aula, que se não chegam a configurar, em sua integralidade, uma prática escolar construtivista de acordo com os autores construtivistas, sinalizam a apropriação do ideário construtivista pelas escolas, apesar de ainda não conseguirem efetivá-lo plenamente na prática, indicando mudanças significativas, em curso, no interior das salas de aula (Miranda, 2000).

O confronto entre o modelo construtivista e as práticas 
escolares estudadas evidencia, especialmente, a relação professoraluno em torno da realização das tarefas escolares, ou seja, a exacerbação da atividade do aluno, ou, ainda, a presença do princípio de que a ação gera a aprendizagem. O que significa que, tanto no ideário construtivista quanto nas práticas educativas observadas, as tarefas escolares passaram a assumir a centralidade do processo ensino-aprendizagem, mediante as quais se manifesta não apenas a ação do aluno, mas ainda a ação do professor. Ou, dito de outra maneira, constata-se que a ação do aluno e a ação do professor, em torno da realização das tarefas escolares, confluem para tornar a ação um instrumento para alcançar um fim, a saber: 0 desenvolvimento das funções cognitivas e a aquisição do conhecimento.

Interessava saber, ainda, se as professoras compreendiam a noção de atividade do aluno, tal como o construtivismo a concebia, tendo em vista que as professoras colocavam os alunos rotineiramente e durante quase todo horário da aula para realizar tarefas escolares. Uma maneira de responder a essa questão é verificar como os autores construtivistas concebem as atividades do aluno. Coll (1994), ao responder a questões semelhantes, referentes a atividades desenvolvidas por crianças em um jardim de infância no contexto da educação espanhola, reporta-se aos conceitos de "atividade de efetuação" e "atividade funcional", propostos por Claparède (1950) para diferenciá-los da designação ativa, isto é, a interpretação de atividade como algo necessariamente exteriorizado e observável. Claparède afirma que a atividade dos alunos pode comportar ou não uma ação externa. Nessa perspectiva, a "atividade funcional" implica interesse do aluno pelo ato que realiza. E a "atividade de efetuação" significa movimento, expressão ou produção, acepção que não leva em consideração, de acordo com Claparède, os interesses dos alunos; ao contrário, valoriza o resultado, a realização da atividade.

Coll acrescenta que o conceito de "atividade autoestruturante", inspirado nos trabalhos de Piaget, enriqueceu a definição de "atividade funcional" elaborada por Claparède, podendo ser compreendida como "aquela atividade que consiste em aceitar um objetivo, cuja origem pode-se encontrar em si mesmo ou em outra pessoa, e em organizar as próprias ações com a finalidade de alcançá-lo" (Coll, 1994, p. 47). Resumindo: enquanto a atividade funcional valoriza que o aluno decida o que fazer, a atividade auto- 
estruturante prioriza que o aluno decida como o faz, que tenha "autonomia para organizar e estruturar as suas atuações" (Coll, 1994, p. 47).

Por último, Coll sinaliza a atividade de escuta, como caraterística do modelo tradicional de ensino, apresentando duas dimensões unicamente como diferença em relação à "atividade de efetuação": "não se considera necessário que, para adquirir o saber ao redor do qual articula-se a tarefa e que consiste a finalidade prioritária, a criança seja ativa, pelo contrário, se exige dela um máximo de atenção às explicações verbais do educador" (Coll, 1994, p. 54).

Apesar de essas definições permitirem constatar os tipos mais freqüentes de atividades utilizadas nas salas de aula dos jardins de infância, elas não bastam, segundo Coll, para analisar uma tarefa escolar em termos de atividade. É necessário, também, considerar a ação do professor e a interatividade professor-aluno.

Dessa forma, Coll elabora sete dimensões didáticas essenciais para a análise da interatividade5: 1) finalidade educativa que o professor pretende alcançar com a tarefa proposta; 2) existência ou não de um saber ao redor do qual se organiza a tarefa; 3 ) planejamento pelo educador da tarefa que o aluno deve realizar; 4) sem intervenções; 5) grau de iniciativa do aluno na escolha da tarefa; e de seu conteúdo; 6) grau de iniciativa do aluno na realização da tarefa; e 7) natureza da atuação requerida do aluno no caso de tarefa fixadas e pautadas. As quatro primeiras referem-se à ação do professor e as três últimas, à ação do aluno. Esclarece que, na análise de tarefas reais, podem-se encontrar configurações que apresentem divergências e contradições em relação aos modelos e às configurações mistas.

A análise das tarefas escolares das seis escolas observadas, utilizando como parâmetro o quadro com as sete dimensões didáticas e as modalidades de atividades, enfocada por Coll, demonstra uma aproximação, em maior ou menor grau, de acordo com a escola, com a noção de atividade auto-estruturante, característica da concepção de ação piagetina, porém mesclada com outras modalidades de atividades, por ele indicadas, como: atividade de efetuação, atividade funcional e a atividade de escuta. O quadro resume as configurações-tipo, predominantemente encontradas nas escolas estudadas. 


\section{Quadro 1}

Configurações-tipo e modalidades de atividade predominante e secundárias encontradas em cada escola observada

Tipos de escolas Modalidades de atividade (predominante e secundárias)

Particular católica Auto-estruturante/ de efetuação/de escuta

Particular protestante De efetuação/ de escuta / autoestruturante

Particular laica Funcional/ auto-estruturante/ de escuta

Pública municipal De efetuação/ de escuta/ autoestruturante

Pública estadual De efetuação/ de escuta/ autoestruturante escuta

Pública federal Auto-estruturante/ de efetuação/ de

A primeira modalidade é a predominante e as demais, secundárias.

O quadro das modalidades de atividades predominantes e secundárias encontradas nas escolas estudadas evidencia uma convivência mista com vários conceitos de ação. As tarefas escolares expressam, às vezes, no mesmo dia, ou até na mesma tarefa, uma concepção de ação piagetiana (auto-estruturante), de ação como algo exteriorizado e observável (de efetuação), de ação mecânica e repetitiva como na escola tradicional (de escuta).

Cabe, no entanto, perguntar: o que é essa atividade autoestruturante? O que expressa a afirmação de Coll de que o aluno deve ter "autonomia para organizar e estruturar as suas atuações" em relação às tarefas propostas pelas professoras? Significa que a atividade a ser priorizada nas tarefas escolares, na perspectiva construtivista, é a atividade mental construtiva, ou a "lógica das ações" (Coll, 1994), ou, ainda, as "ações como operações" (Macedo, 1994), bem como o desenvolvimento dos quadros lógicomatemáticos (Piaget, 1973), e não apenas uma atividade física, externa e observável. 
Priorizar a atividade mental construtiva significa considerar a atividade interna e mental como elemento essencial para adquirir o conhecimento e a possibilidade de interpretar a realidade, não desconsiderando, desqualificando ou negando a atividade física. Priorizar a atividade auto-estruturante é, supostamente, possibilitar o desenvolvimento da autonomia de pensamento do aluno. A atividade ganha, portanto, no construtivismo, uma dimensão cognitiva, construtiva e essencial para o processo de conhecimento. A ação torna-se o meio e o fim do processo educativo.

As tarefas escolares são, assim, os meios educativos que podem permitir ao aluno desenvolver suas funções cognitivas e as formas de apreensão e organização do real, como: selecionar, comparar, organizar, estabelecer relações, tirar conclusões, levantar hipóteses, problematizar, usar e gerar conhecimentos, com autonomia, levando em consideração a necessidade da manipulação e da experimentação de objetos, quando necessárias ao desenvolvimento das coordenações entre as ações. Significa que, para ocorrer a atividade do aluno, segundo a perspectiva construtivista, é necessária a ocorrência de dois fatores: a autonomia do aluno, ou seja, que o aluno decida como realizar a tarefa, e que essa priorize o desenvolvimento das funções cognitivas.

A ação do professor é propiciar situações de aprendizagem, dentre elas, tarefas escolares, que permitam ou possibilitem ao aluno desenvolver suas funções cognitivas, aprender a fazer uso dessas funções e a criar hábitos de utilização dessas capacidades, de modo independente e autônomo.

Ainda que os autores construtivistas afirmem que recorrem à teoria de Vygotsky para "deslocar o centro do interesse da atividade auto-estruturante para os processos de interação professor-aluno que a desencadeiam e a promovem" (Coll, 1994, p. 101), essa compreensão vai ao encontro dos postulados teóricos de Piaget, sendo fiel à compreensão do desenvolvimento mental como algo espontâneo, natural e individual. Também vê o professor não como um palestrante, mas como um "animador", um "estimulador", como o próprio Piaget (1998, p. 139) afirma: "A criança não é um ser passivo cujo cérebro deve ser preenchido, mas um ser ativo, cuja pesquisa espontânea necessita de alimento". Para tanto, postula que um ensino adequado pode propiciar, estimular e favorecer o desenvolvimento das operações lógico-matemáticas.

Conseqüentemente, o professor, os colegas e os recursos 
didáticos não são responsáveis pela construção ou pela qualidade da construção ou pela reconstrução dos esquemas de conhecimento, tendo em vista que esses dependem de esquemas assimilativos construídos anteriormente, nas interações e trocas com o meio. A interação com os professores, com os colegas e a manipulação ou observação de materiais didáticos podem, no entanto, desencadear as ações mentais do aluno.

Nesse sentido, pode-se responder à questão formulada, afirmando não se verificar, nas práticas educativas estudadas, 0 significado integral da atividade do aluno comportando seus dois aspectos essenciais: a autonomia e a atividade auto-estruturante. Porém, a acepção de ação predominante é eminentemente piagetiana, apesar de apresentar-se como um simulacro, uma vez que a presença dessa atividade, com maior ou menor incidência, conforme a escola, vem sempre mesclada a outras concepções de ação.

\section{A ação como princípio pedagógico}

A constatação de que as tarefas escolares assumem um lugar central na prática pedagógica contemporânea e de que essas tarefas têm, na prática construtivista, uma dimensão autoestruturante, mesclada com outras modalidades de atividade, remete à discussão de um conceito que, ao longo do século XX, permeia a discussão no campo educacional: a ação como princípio educativo.

$\mathrm{Na}$ tentativa de compreender a centralidade das tarefas escolares nas práticas construtivistas ou o que expressa essa exacerbação do conceito de ação nas práticas escolares contemporâneas, recorreu-se a alguns teóricos do século XX que sustentam o princípio de que a ação gera a aprendizagem, como Jean Piaget, Lev S. Vygotsky e John Dewey.

A acepção de ação de Jean Piaget que se evidencia, ao longo de seus escritos, é uma concepção biológica e adaptativa, uma vez que a idéia de continuidade entre os processos biológicos e os processos cognocitivos permanece presente em toda a obra do psicólogo genebrino.

Nessa perspectiva, pode-se citar, inicialmente, o livro $O$ nascimento da inteligência na criança, no qual Piaget (1975, p. 13) sustenta que "existe uma certa continuidade entre a inteligência e 
os processos biológicos de morfogênese e de adaptação ao meio".

Nessa obra, para explicar a conversão da inteligência prática, apoiada em estruturas biológicas, em uma inteligência reflexiva, Piaget define inteligência como um processo adaptativo, compreendendo a adaptação como a essência do funcionamento, tanto intelectual como biológico, e o elo que estabelece a continuidade entre a biologia, em geral, e a inteligência, em particular, é o mecanismo funcional de pensamento denominado de invariantes funcionais, a saber: a organização e a adaptação.

No livro Biologia e conhecimento (1973), considerada uma obra da maturidade e sua obra máxima, Piaget, apesar de procurar evidenciar não só as correspondências das funções e os isomorfismos das estruturas entre os organismos e os mecanismos cognoscitivos, mas, ainda, as originalidades e especificidades dos segundos em relação aos primeiros, permanece apoiado teoricamente na idéia de continuidade entre esses processos.

Explica, nesse livro, que o prolongamento da ação em operação dá-se mediante a construção das estruturas lógico-matemáticas que, no sentido psicológico, é chamada por Piaget de abstração reflexiva, ou seja, a abstração reflexiva é a construção de um órgão regulador, que organiza todo o funcionamento do processo psicogenético das estruturas operatórias. Desse modo, a ação só se prolonga em operação, "após a reconstrução dessas estruturas práticas em estruturas de pensamento", efetuadas retrospectivamente pela abstração reflexiva (Piaget, 1973, p. 364).

A construção das estruturas lógico-matemáticas permite a Piaget inferir que a inteligência humana encontra, por intermédio do pensamento lógico-matemático, um instrumento de adaptação ao meio físico e social, cada vez mais independente da experiência e de conquista de possibilidades mais amplas e profundas do que as permitidas pelas estruturas orgânicas, o que permite ao homem lançar-se ao mundo das possibilidades, podendo alcançar sua autonomia de pensamento.

Nesse sentido, as originalidades e as especificidades dos mecanismos cognoscitivos em relação às estruturas biológicas, enfocadas por Piaget, não só reafirma a vinculação da ação a uma estrutura biológico-adaptativa, uma vez que a fonte das estruturas lógico-matemáticas são as coordenações gerais das ações, bem como, ainda, confere à ação uma dimensão interna, mental, individual, ao sugerir a construção de um órgão regulador interno que 
realizaria e concretizaria a passagem da ação em operação. Significa que o elo teórico que permite estabelecer uma analogia entre os processo biológicos e os cognoscitivos é o conceito de ação. $O$ princípio da atividade está presente nas contínuas trocas entre o organismo e o meio, da mesma maneira que é sobre as ações internalizadas e convertidas em operações que as estruturas lógicomatemáticas passam a se constituir. A ação, com a construção das estruturas formais, ganha uma dimensão endógena, construtiva, operatória e cognitiva.

Ao confrontar a concepção de inteligência piagetiana com a modalidade de atividade auto-estruturante, enfocada por Coll (1994), verifica-se que, de fato, este último inspirou-se nos trabalhos piagetianos para elaborar sua definição de ação, uma vez que também converte a ação física e externa em uma ação interna, mental e operatória e a compreende como a inteligência propriamente dita.

Nesse sentido, a ação para Piaget e para Coll é a inteligência ou atividade auto-estruturante, e essa se constrói mediante a ação do sujeito sobre os objetos de conhecimento. A ação, assim, é vista como parte inerente e constitutiva do processo de conhecimento.

Cabe, contudo, questionar se o outro, o professor ou os processos de ensino podem incidir sobre os processos de desenvolvimento na teoria piagetiana. Parrat-Dayan e Tryphon (1998), que organizaram, recentemente, uma coletânea de artigos de Piaget sobre educação, afirmam que a reflexão pedagógica não foi a temática central da sua obra. Entretanto, sustentam que, a despeito disso, as preocupações e as reflexões pedagógicas sempre estiveram presentes e acompanharam suas reflexões epistemológicas.

Nas reflexões pedagógicas de Piaget, verifica-se uma ardorosa e recorrente defesa dos métodos ativos do século XX, especialmente os desenvolvidos por Dewey, Claparède, Decroly, dentre outros, bem como a tentativa de evidenciar a perfeita consonância entre esses métodos e suas pesquisas sobre o desenvolvimento mental da criança e do adolescente.

Segundo Piaget6 (1998), há um desenvolvimento mental espontâneo que cabe à escola alimentar, complementar e ampliar, por meio de um ensino adequado. $O$ ensino adequado para favorecer o desenvolvimento das operações lógico-matemáticas não é outro senão o operado pela escola ativa e seus métodos inovadores. Esses métodos provocam no aluno a tomada de consciência de 
problemas que, em parte, ele mesmo já se coloca; estimulam a pesquisa espontânea da criança e do adolescente, fornecem a possibilidade de aprender, por meio das ações de manipulação e experimentação, e a alcançar a autonomia de pensamento, não necessariamente nessa ordem.

Nesta perspectiva, cabe ao professor conhecer bem o desenvolvimento psicológico da inteligência infantil e do adolescente e propiciar situações de aprendizagem que possam desencadear a atividade mental e interna. O que também evidencia a influência da teoria genética de Piaget na concepção de ação do professor de Coll, entendido como aquele encarregado de oferecer as condições para o desenvolvimento da atividade auto-estruturante do aluno.

Pode-se depreender que o conceito de ação que prevalece na acepção construtivista é a noção de ação piagetiana, apesar da tentativa dos construtivistas de recorrerem a Vygotsky.

Diferentemente, o conceito de ação em Vygotsky sugere uma aproximação com o conceito de trabalho, na suposição que a ação é constitutiva e constituinte do próprio homem, visto que o homem, ao interiorizar as formas produzidas social e culturalmente, ao longo do curso de desenvolvimento do homem, e delas se apropriar, constitui novas formas de comportamento e sua própria consciência.

Vygotsky, em seu livro A formação social da mente (1991), explica que a ação possui inicialmente uma dimensão externa, social e interativa, ou seja, é por intermédio das relações concretas que o indivíduo estabelece com os outros homens que se apropria das formas culturalmente dadas de compreender e organizar o real; somente depois disso, é que essa ação se torna interna, um instrumento psicológico de mediação entre o indivíduo e o mundo.

Nesse enfoque, a escola, o professor, os colegas e os processos de ensino são elementos essenciais na constituição do homem como ser genérico e individual. Cabe ao professor possibilitar ao aluno apropriar-se da produção social/cultural da humanidade, mediar entre os conhecimentos cotidianos do aluno e os conhecimentos científicos da escola, propiciar as situações de aprendizagem das formas culturais de uma dada sociedade, mediante a intervenção e a assistência de outras pessoas.

A autonomia é alcançada, para Vygotsky, com base na internalização e representação dos signos e instrumentos produzidos social e culturalmente, possibilitando ao indivíduo desempenhar 
funções e habilidades, superar obstáculos e resolver problemas sem auxílio.

Ao confrontar o conceito de atividade de Vygotsky com o conceito de ação, enfocado pelos construtivistas, não se encontram afinidades. Portanto, pode-se afirmar que a ação construtivista é eminentemente piagetiana. Deve-se ressaltar, ainda, que as matrizes biológicas e filosóficas do conceito de ação piagetiano aproximam-no do conceito de ação do pragmatismo americano, especialmente da vertente instrumentalista de John Dewey.

Dewey, em seu livro Reconstrução em filosofia (1959), promove uma revisão rigorosa e sistemática da filosofia clássica e do próprio pragmatismo, propondo investigar o significado da experiência humana nas teorias filosóficas. Em sua análise, elabora uma nova concepção de experiência, e uma nova relação entre ação e pensamento.

As influências das categorias biológicas, segundo Wright Mills (1968, p. 391), levaram Dewey a "naturalizar" a mente e a compreendê-la como uma função biológica. Assim, o instrumentalismo considera o pensamento como um processo, "como um modo de adaptação orgânica ao meio", e todo seu desenvolvimento é determinado nessa e por essa relação. De acordo com essa concepção, o funcionamento mental é considerado instrumental e adaptativo; e o conhecimento é "relegado para posição derivada, secundária quanto à origem, embora sua importância, quando estabelecida, seja dominante, suprema" (Dewey, 1959, p. 105).

Para Dewey, como a experiência objetiva é direcionada para uma busca de melhor adaptação do organismo ao meio, então possui os princípios de conexão e de organização, antes exclusivos do domínio da razão superempírica. Esses princípios possibilitam as condições para o desenvolvimento da inteligência, que acaba por se constituir no conteúdo da própria reflexão, ao se tornar seu fator interno de organização. Daí, a razão é algo que nasce e se comprova na experiência.

Esse novo lugar da razão na experiência converte a razão em inteligência, ou melhor, em uma inteligência experimental, concebida nos moldes da ciência. A inteligência converte-se, nessa perspectiva, em uma forma de organização da experiência, constitui-se em um instrumento que o homem utiliza e a que recorre para conseguir vencer ou superar os obstáculos encontrados no meio. 
Nesse sentido, em seu livro Democracia e Educação,7 Dewey (1979, p.83) define a educação como uma "reconstrução ou reorganização da experiência, que esclarece e aumenta o sentido desta e também a nossa aptidão para dirigirmos o curso das experiências subseqüentes". A rigor, isso significa que a experiência é um processo ativo, contínuo e sucessivo e que se prolonga no tempo. $O$ conceito de experiência constitui o elemento essencial da teoria educacional de Dewey, pois o ato de pensar inicia-se na e com a experiência. Daí que, para ele, o ato de pensar que não se refere à experiência e aos assuntos sobre os homens e o mundo em que vivem não pode ser considerado pensamento.

Por isso, afirma a necessidade de uma revisão na forma de compreender os métodos de ensinar e aprender, e indica que o único caminho é não separar os conhecimentos informativos da ação reflexiva. Assim, esses métodos devem priorizar as condições que estimulam, promovem e põem à prova a reflexão e o pensamento. O "ato de pensar é o método de se aprender inteligentemente" (Dewey, 1979, p. 167).

O seu método de ensinar e de aprender consiste em o professor oferecer situações ou experiências que sejam novas, e que suscitem no aluno a vontade, o interesse de fazer alguma coisa para resolvê-las situações-problema que, com certeza, resultarão em uma reflexão e, por conseguinte, em uma aprendizagem. $\mathrm{O}$ professor, nesse enfoque, não é um transmissor de conhecimentos, mas quem oferece as condições pedagógicas, cria as situações de aprendizagens, estimula a pesquisa, para que os alunos possam aprender a aprender, em um processo de atividade compartilhada, 8 entre professores e alunos, em que ambos estabeleçam as interconexões entre a escola e a sociedade, entre a teoria e a prática, efetivando a união entre o pensamento e a ação.

A concepção de ensinar e de aprender de Dewey, que enfatiza uma ação do aluno, uma ação do professor por meio de tarefas escolares, consiste em uma compreensão do processo de ensino-aprendizagem como ocorrendo em torno de atividades compartilhadas, o que parece muito mais condizente com a compreensão de interação social, enfocada por Coll (1994), do que com o entendimento de Vygotsky.

Afirma-se, então, que a perspectiva construtivista encontra sua inspiração teórica na acepção de ação piagetiana, apropriandose de sua dimensão endógena, construtiva, constitutiva e operatória 
do processo de conhecimento, e busca sua justificativa teórica na filosofia pragmática, especialmente na vertente instrumentalista de John Dewey, para sustentar o princípio de que a ação gera a aprendizagem, ou, ainda, para converter a ação em princípio educativo.

Considerações finais

Pode-se, nesse momento, questionar: o que expressa a exacerbação da atividade do aluno? Ou, ainda, o que significa a predominância de uma concepção de ação de caráter eminentemente adaptativa e instrumental para o pensamento educacional?

As implicações teóricas e práticas dessa forma de conceber as ações humanas podem ser buscadas nas análises históricas e filosóficas que os membros da denominada Escola de Frankfurt empreenderam sobre a constituição da racionalidade humana, que, em vez de possibilitar a emancipação do homem, tem produzido o seu inverso a dominação e a opressão.

A racionalidade sob o signo da dominação é a racionalidade científica, característica da filosofia positivista e pragmática, que revela a crença no poder da lógica formal, da ação racional, para evidenciar e demonstrar as relações entre os acontecimentos, e não a compreensão dos elos com os processos sociais reais (Horkheimer, 1976 e 1980). Dito de outra forma, a explicação do real passa a ser condicionada às leis lógicas e racionais dos métodos matemáticos, e não ao movimento do real, de alterações no mundo da produção e do trabalho.

Nesse processo, o pensamento é confundido com os procedimentos matemáticos, transforma-se em instrumento que serve para classificar, ordenar, seqüenciar e organizar o mundo e as coisas, bem como se identifica com o objeto e com o processo de pensar o pensamento, enfim com o formalismo matemático.

No mundo reificado, como não há contradição, o homem é naturalizado e vê-se preso à imediaticidade, à matéria, ao dado bruto, não lhe restando outra alternativa senão a aceitação e a adaptação ao eterno, ao nada novo. Amarrado ao factual, torna-se preso aos seus princípios determinantes negadores de injustiça, de desigualdade e de opressão, alienando-se das coisas e de si mesmo.

Nesse sentido, o modelo construtivista dos processos escolares, enfocado por Coll (1994), fundamentado essencialmente pela 
teoria genética de Piaget e justificado pelo pragmatismo de Dewey, concorre para a instrumentalidade do ato de pensar, para converter o pensamento em um mero instrumento, que serve para classificar, ordenar, organizar o mundo e as coisas, transformando a razão humana em instrumento privilegiado para superar obstáculos e solucionar problemas imediatos do dia-a-dia, visando à melhor adaptação do homem ao meio.

Isso porque esse modelo visa priorizar o desenvolvimento da atividade auto-estruturante, o desenvolvimento das funções cognitivas que servem de instrumento para a apreensão e a organização do real, o desenvolvimento das estruturas lógico-matemáticas, das formas lógicas que possibilitam ao indivíduo apreender, compreender e intervir na realidade. Assim, a inteligência privilegiada é a inteligência do cientista, conforme os imperativos matemáticos e científicos norteadores de um determinado tipo de racionalidade a racionalidade instrumental.

Pode-se, no entanto, argumentar sobre o problema daí decorrente, uma vez que as exigências sociais contemporâneas preconizam o desenvolvimento de indivíduos autônomos, que tenham iniciativa, que saibam buscar, pesquisar e selecionar informações relevantes e resolver problemas cotidianos.

De fato, as novas demandas e exigências do mundo do trabalho concorrem para a formação desse tipo de trabalhador, contudo a constituição dessa racionalidade instrumental, essa conversão do pensamento em uma coisa, em um instrumento solucionador de problemas, em um instrumento de relacionar e equacionar meios e fins, acaba por compreender a atividade humana como dirigida apenas para a adaptação do homem às condições materiais de existência, subordinando a liberdade às necessidades. No limite, condicionando a liberdade aos interesses do mercado e do capital, desta forma, constituindo uma subjetividade não-autônoma.

A racionalidade instrumental bane a possibilidade de emancipação humana, ao negar a possibilidade de estabelecer nexos entre os acontecimentos e os fatos reais, tomando como referência o mundo do trabalho e da produção e ao sustentar e manter a separação sujeito/objeto, corpo/mente e homem/natureza, uma vez que privilegia os imperativos matemáticos e científicos.

Nesse sentido, a racionalidade instrumental forja uma versão de que o desenvolvimento humano, a manutenção e a continuidade 
da sociedade passam, necessariamente, pelo caminho da apreensão, da apropriação e da utilização do conhecimento científico e técnico, por intermédio de uma educação que deve criar e oferecer as condições que propiciem o desenvolvimento mental, emocional e moral que são exigidos e necessários para a inserção do indivíduo no mundo das relações sociais de produção. Relega ao esquecimento e bane da filosofia, e da história da filosofia, outras possibilidades de liberdade e emancipação do homem.

No conceito ou no significado das tarefas escolares, no meio educacional, como elemento de mediação entre a ação e a aprendizagem residem, porém, não só o caráter instrumental da ação, mas, ao mesmo tempo, o caráter reflexivo e elucidativo de ação. As tarefas escolares tanto podem ser elaboradas ou propostas para propiciar o desenvolvimento e exercitar o uso das funções cognitivas dos alunos, como também podem ser organizadas de modo a possibilitar aos alunos uma ação reflexiva e elucidativa sobre si mesmos, sobre o mundo em que vivem e sobre a realidade. Essa ação reflexiva possibilita estabelecer nexos entre os acontecimentos e fatos reais, tomando como referência o mundo do trabalho, e, assim, interpretar melhor a realidade.

\section{ABSTRACT}

This essay discusses the central role that the scholar works assumed in the learning-teaching process in the educacional contemporaneous practices. The centrality of the scholar works expresses the construtivist goal translation that the student knowledge construction comes from his action. The action concept finds its basement in the Piaget genetic theory and justifies theory in John Dewey pragmatism.

KEYWORDS: scholar works, action, phsycologic theories.

\section{NOTAS}

1. Na falta de uma designação mais abrangente manteve-se o termo construtivismo para designar essas práticas escolares contemporâneas assumidamente fundamentadas em teorias psicológicas e caracterizadas pela ênfase na ação do aluno na construção ativa de seu conhecimento. 
2. Pesquisa coordenada pela Prof ${ }^{\mathrm{a}} \mathrm{Dr}^{\mathrm{a}}$ Marília Gouvea de Miranda, com a participação da Profa Mona Bittar, com financiamento do CNPq, no período de 1995 a 1999. A pesquisa foi dividida em dois subprojetos: A produção teórica sobre o construtivismo e $O$ construtivismo enquanto proposta pedagógica e sua efetivação na escola, que contaram com a colaboração de bolsistas de Iniciação Científica.

3. Nesse sentido, em todas as escolas observadas, uma classe de alfabetização,ou classe de iniciantes, precedia a primeira série, voltada para o desenvolvimento da leitura e da escrita e dos cálculos matemáticos fundamentais.

4. Assessor da Direção-Geral da Renovação Pedagógica da Espanha, considerado um dos pais da reforma educativa espanhola, bem como um dos autores que têm contribuído para a retórica da reforma educacional brasileira.

5. Ver neste sentido, Coll, César. Natureza e planejamento das atividades no jardim de infância. Aprendizagem escolar e construção do conhecimento. Porto Alegre: Artes Médicas, 1994.

6. Nesse sentido, ver os artigos: "Observações psicológicas sobre o ensino elementar das ciências naturais" e a "A iniciação à Matemática, a matemática moderna e a psicologia da criança". In:

PIAGET, J. Sobre a pedagogia: textos inéditos. São Paulo: Casa do Psicólogo, 1998.

7. Essa obra é considerada por Dewey seu melhor livro, e por muitos estudiosos de seu pensamento, a apresentação mais completa de sua teoria educacional, o conteúdo de sua formulação de uma nova filosofia e de sua teoria do conhecimento.

8. Segundo Dewey (1979), na atividade compartilhada com os outros membros do grupo, o indivíduo estabelece a correspondência entre suas ações e as ações dos outros. Essa harmonização cria a identificação entre a atividade do indivíduo e a atividade do grupo, despertando no indivíduo os mesmos sentimentos, as mesmas idéias, os mesmos hábitos mentais que sentem os companheiros. 


\section{REFERÊNCIAS}

ADORNO, T. e HORKHEIMER, Max. Dialética do esclarecimento: fragmentos filosóficos. Rio de Janeiro: Zahar, 1985.

BROOKS e BROOKS, Jaqueline e Martin. Construtivismo em sala de aula.

Porto Alegre: Artes Médicas, 1997.

COLL, César. Aprendizagem escolar e construção do conhecimento. Porto Alegre: Artes Médicas, 1994.

CLAPARĖDE, Emund. A educação funcional. 3. ed. São Paulo:

Companhia Editora Nacional, 1950.

DELVAL, Juan. Aprender a aprender. Campinas, SP: Papirus, 1997. DEWEY, John. Reconstrução em filosofia. São Paulo: Companhia Editora Nacional, 1959.

Nacional, 1979. Democracia e educação. 4. ed. São Paulo: C. E.

GARCIA, Rolando. Criar para compreender: a concepção piagetiana do Conhecimento. In: TEBEROSKY, A. e TOLCHINSKY, L.

Substratum : temas fundamentais em Psicologia e Educação.

Porto Alegre: Artes Médicas, 1997.

HORKHEIMER, Max. Eclipse da razão. Rio de Janeiro: Editorial Labor do Brasil, 1976.

MIRANDA, Marília G. Trabalho, educação e construtivismo. A redefinição da inteligência em tempos de mudanças tecnológicas. Educação e Sociedade,Campinas, v. 16, p. 234 - 337, ago. 1995. Pontifícia Universidade Católica/SP, 1991. Razão e adaptação. Tese (Doutorado)-

nal. Campinas, SP: Autores Associados, 2000.

PARRAT-DAYAN e TRYPHON (Org.). Sobre a pedagogia: textos inéditos. São Paulo: Casa do Psicólogo, 1998.

PIAGET, Jean. Biologia e conhecimento: ensaio sobre as relações entre as regulações orgânicas e os processos cognoscitivos.

Petrópolis, RJ: Vozes, 1973.

. O nascimento da inteligência na criança. 2. ed. Rio

de Janeiro: Zahar, Brasília: INL, 1975.

VYGOTSKY, L. S. A formação social da mente. 4. ed. São Paulo: Martins Fontes, 1991. 
1 Este texto é resultado da pesquisa de dissertação de mestrado intitulada As tarefas escolares como mediação entre a ação e a aprendizagem: instrumentalização ou autonomia, sob orientação da Prof ${ }^{a}$ Dr ${ }^{a}$ Marília Gouvea de Miranda, no mestrado em Educação Brasileira na Faculdade de Educação-UFG, jul. 2000. $2^{\star *}$ Professora da Faculdade de Educação-UFG. 